\title{
Fat Body Development and its Function in Energy Storage and Nutrient Sensing in Drosophila melanogaster
}

\section{Yafei Zhang and Yongmei $\mathrm{Xi}^{\star}$}

Institute of Genetics, College of Life Sciences, Zhejiang University, China

*Corresponding author: Yongmei Xi, Institute of Genetics, College of Life Sciences, Zhejiang University, China; Tel: +86-571-88206623; Fax: +86-571-88981371; Email: xyyongm@zju.edu.cn

Received date: May 04, 2014; Accepted date: Sep 29 2014; Published date: Oct 03, 2014

Copyright: (c) 2014 Zhang Y, et al. This is an open-access article distributed under the terms of the Creative Commons Attribution License, which permits unrestricted use, distribution, and reproduction in any medium, provided the original author and source are credited.

\begin{abstract}
The fat body of Drosophila has been considered as the equivalent to the vertebrate adipose tissue and liver in its storage and major metabolic functions. It is a dynamic and multifunctional tissue which functions in energy storage, immune response and as a nutritional sensor. As a major endocrine organ in Drosophila, the fat body can produce various proteins, lipids and carbohydrates, synthesize triglyceride, diacylglycerol, trehalose and glycogen in response to energetic demands. It also secretes significant proteins governing oocyte maturation or targeting nutritional signals in the regulation of the metabolism. At different developmental stages and under different environmental conditions the fat body can interplay with other tissues in monitoring and responding to the physiological needs of the body's growth and to coordinate the metabolism of development. The Drosophila fat body exists as a model relating to human lipometabolic disease, puberty and maturation and age-related diseases such as cancer, obesity and diabetes. In this review, we summarize the fat body formation and maturation in the Drosophila life cycle and provide an overview of fat body function as an energy reservoir and nutrient sensor. We also discuss the signaling pathways and key regulatory factors involved.
\end{abstract}

Keywords: Drosophila; Fat body; Energy storage; Nutrient sensor

\section{Introduction}

The Drosophila fat body provides an ideal system for the study of insect energy storage and nutrient sensing. The Drosophila fat body is active in sensing nutritional conditions and can synthesize and release energy [1]. It secretes key factors related to brain development and body size [2]. It is an important location for many aspects of the intermediary metabolism [3-4]. During metamorphosis or starvation, fat cells undergo autophagy. Fat body cells contain a substantial number of fat droplets which are mainly composed of triglyceride [5-6]. Many proteins and peptides have been identified to play specific roles in fat body development. These include PAT domain containing lipases such as Brummer and Perilipin which regulate fat body storage [7-9], and BFTZ-F1 and Matrix metalloproteinase 2 (MMP2) which are involved in fat body remodeling [10-11].

The fat body can secrete proteins and peptides to directly affect the development of other organs and tissues. Examples include IDGFs effect on wingdisc growth [12], and the secretion factors Drosophila insulin-like peptide (Dilps), which effect insulin producing cells in the brain [3]. The evolutionarily conserved pathways and key regulators that exist between insects and mammals emphasize the value of the Drosophila fat body as a genetic model for the study of the mechanisms and therapies relating to human lipometabolic disease, the control of puberty and maturation in humans and age-related diseases such as cancer, obesity and diabetes.

\section{The Development of Fat Body in Drosophila}

The Drosophila fat body is derived from the embryonic mesoderm [13-15]. With cell specific marker genes, such as Adh [16], DCg1 [17], svp [18], srp [19] and an enhancer trap 29D [20], scientists have identified the various stages of fat-body development starting from stage 10/11 during embryogenesis. During stages 11 to 14 , progenitor fat cells arise from 9 bilateral clusters of cells in the inner mesodermal layer, spanning parasegments 4 through 12. Specific precursor-cell clusters that lie in the lateral, ventral, and dorsal mesoderm give rise to the fat cells (Figure 1a) [20-22]. By late stage 15/16, these cells coalesce into a single-cell thick fat body layer containing three domains: the lateral fat body, the dorsal fat-cell projection and the ventral collar (Figure 1b) [23]. The fat body exists mainly in the abdomen, but the thorax and head also contain some extended parts. Development of the embryonic fat body requires the expression of the GATA transcription factor Srp, without which the fat body progenitors undergo apoptosis [24,25].

During various stages of fat-body development, each morphological region of the fat body is thought to arise from spatially distinct precursor-cell clusters. However, to date only a proportion of these progenitor fat cells have been identified. This is due to the lack of a specific and versatile marker that covers all fat body progenitor cells. When fat-cell differentiation begins, the molecular mechanisms that control the final steps of cell specification have also not yet been fully elucidated. In Drosophila, cells in the posterior larval fat body store more protein granules than do the ones in the anterior fat body [26]. This suggests the distinct functions of different domains within the fat body. Further investigation on functional domains within the embryonic fat body may reveal many interesting aspects relating to this.

By the end of embryogenesis, the fat body consists of approximately 2200 cells, fat cells number remains constant and only increase in volume throughout larval development [27-29]. During pupal stages, the fat body undergoes changes in shape, size, and function in a process termed "fat body remodeling". At approximately 6 hours after 
pupariation formation (APF), fat cells begin to lose their polygonal shape and become spherical. This persists between 6 and 12 hours APF, the change aggravating with time. By 14 hours APF, fat cells have become detached from each other and are eventually completely disassociated [11,30-31]. The larval-pupal transition is mainly regulated by the steroid hormone 20-hydroxyecdysone (20E) and the sesquiterpenoid hormone juvenile hormone [32]. Signals that trigger the onset of ecdysteroidogenesis contain the prothoracicotropic hormone (PTTH), which is a neuropeptide released from the brain. PTTH binds to its receptor, Torso, and causes transcript levels ecdysteroidogenic enzymes to be upregulated through the MAPK signaling pathway [33-38]. This, in turn, regulates the timing of metamorphosis. During the metamorphosis, autophagy and apoptosis are induced by $20 \mathrm{E}$ in the fat body and the balancing crosstalk between them is predominantly transduced by E93, a primary-response gene of 20E [39-41]. The two matrix metalloproteinases MMP1 and MMP2 are activated by $20 \mathrm{E}$ and coordinate to promote fat cell dissociation while the $\mathrm{JH}$ action prevents 20E-induced apoptosis and cell dissociation [39,42-44].

Both before and after the metamorphosis, Drosophila undergoes a period of non-feeding times. After eclosion, the newly emerged adult remains inactive in feeding. Enough larval energy storage must be available for the survival of these young adults. The free floating fat cells seen in the young adult are the result of the dissociation of the fat body cells during tissue remodeling and only a few of these fat cells persist in the adult, persisting only up to about two days, after which they undergo programmed cell death and are replaced by the adult fat body [45]. These fat cells are nutritionally important during the early, non-feeding stage of adulthood and are critical to the ovary maturation in female adults. These remaining larval fat cells are also thought to contribute to stress resistance in adults $[27,45]$.
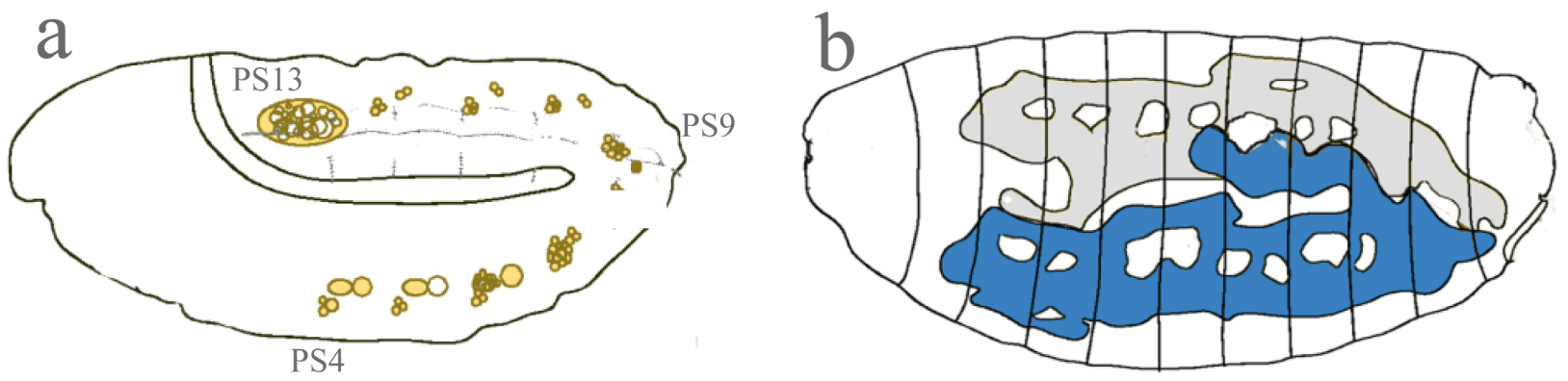

Figure 1: Schematic of precursor fat-cell clusters and fat body domains in the embryo.(a) Stage 12/13 embryo. Progenitor fat cells arise from 9 bilateral clusters of cells (yellow dots), spanning parasegments (PS) 4 through 12. In the PS13 region lies a large cluster of cells which likely make up the dorsal fat-cell projections. (b) Stage 15/16 embryo. During late stages of the embryo, mature fat cells coalesce into a single-cell thick fat body layer and most expand in the abdomen region, forming three domains: the lateral fat body, the dorsal fat-cell projection and the ventral collar.

\section{Function as an Energy Reservoir}

The fat body serves as a key dynamic tissue that controls energy storage and utilization to meet the energy demands of the fly during development. This tissue can take up the fatty acids, proteins or dietary carbohydrates and convert them to triglycerides, whose degraded products through lipolysis are transported to various target tissues to support growth and survival in response to the energy demands $[6,46-47]$. In the fat body the energy storage form is mainly the lipids presented as triacylglycerol, which are stored in lipid droplets. Drosophila fat body cells are full of lipid droplets (LDs) which can be visualized using a Nile red neutral lipid stain or the BODIPY fluorescent dye. The structure of lipid droplet consists of a core of neutral lipids surrounded by phospholipid monolayer and they are decorated with a variety of LD-associated proteins [48-50].

The mobilization of stored fat is essentially regulated by the neuropeptide $\mathrm{AKH}$ (adipokinetichormon) [51]. In the fat body $\mathrm{AKH}$ stimulates the conversion of stored glycogen to hemolymphtrehalose and triglyceride to diglyceride, and in fat body cells of AKH mutant accumulate more body fat. AKH-stimulated lipolysis in the Drosophila fat body relies on signaling via a G protein-coupled receptor, Adipokinetic hormone receptor (AKHR) [52]. However, except the ligand and receptor (AKHR) of $\mathrm{AKH}$, little is known about its downstream regulators, and other ligands and receptors for the $\mathrm{AKH}$ signaling pathway awaiting acknowledgment.

The lipid droplets in the fat body are dynamic organelles and play a central role in the energy metabolism [53]. Many lipid dropletassociated proteins that are involved in this metabolism have been identified [7,54]. Brummer (bmm) is the homolog of mammalian adipose triglyceride lipase (ATGL) which encods a LD-associated triglyceride (TG) lipase, functions to stimulate lipolysis and control the systemic TG levels of the adult fly in a dose-dependent manner. Knockdown of bmm leads to the accumulation of lipid storage, while overexpression protects flies against high fat diet-induced TG accumulation and cardiac dysfunction [55-57]. The phenotype of the bmm mutant seems similar to that of the $\mathrm{AKH}$ signaling mutant, and the loss of both Brummer and AKHR causes a more extreme phenotype than or either single mutant. However, several evidences support that these are, in fact, two different fat-mobilization systems. In bmm mutants, overexpression of $\mathrm{AKH}$ can reduce the excessive TAG (Triacylglycerol) storage, whereas in AKHR mutants, bmminduced fat mobilization is inactive [52]. Future studies will uncover the crosstalk between the two Drosophila lipocatabolic systems, and the identification of the upstream regulators of bmm will be the key step in this.

In Drosophila the best characterized lipid droplet protein is Perilipin. There are two members of the Perilipin family, Lipid storage 
droplet-1 (Lsd1) and Lipid storage droplet-2 (Lsd2). Lsd2 promotes lipid accumulation, whereas Lsd1 stimulates triglyceride hydrolysis $[50,58,59]$.

During larval and adult fly life, Lsd1 is expressed mainly in the fat body. Lsd 1 mutant flies are lipolysis-impaired and develop adult-onset obesity. Phosphorylation of Lsd1 triggers the lipolytic action of AKH and translates the lipolytic signal to the AKH/AKHR pathway [47]. Depletion of Lsd1 causes giant LDs and accompany the increase of Brummer lipases [47]. This indicates that the activity of Brummer lipase is independent of AKH. However, whether Lsd1 regulates the activity of bmm remains to be determined.

Lsd2 is detectable in the fat body during larval stages and is required for normal storage of triglyceride in the fly [60,61]. Lsd1 Lsd2 double mutant flies form LDs and exhibit an impaired but functional storage lipid homeostasis [47]. This suggests a Perilipin-dependent body fat storage control system is not essential for the lipid metabolism and the accurate role of such a control system in the lipid metabolism remains to be shown. Compared with Lsd1, bmm and Lsd2 double mutants have wild-type TAG levels and cooverexpression of them in the fat body can partially rescue phenotypes caused by the overexpression of each of the two genes [55-57]. These observations indicate the opposing roles of Brummer and Lsd2.

In addition to the genetic level, in recent years models of nutrientrelated lipid metabolic homeostasis in Drosophila have also been established. These include high-fat-diet induced (HFD) or high-sugardiet induced (HSD) obesity and diabetes. These provide a highlight on mammal metabolic diseases such as obesity and lipodystrophy.

The lipid metabolism is a complex network in which various organs tightly communicate to integrate the information on energy intake and expenditure to ensure the proper storage fat homeostasis. Though it has been known that lipids are involved in oogenesis and embryo development [62-64], due to less availability of mutants of lipid droplet, the precise function of lipids during drosophila early development are largely unknown. In addition, numerous other regulators of the lipid droplet metabolism vary in expression during the life cycle of Drosophila and have been identified and to perform diverse functions [65-70]. Nevertheless, many of these remain not well characterized. More work needs to be done to provide a clearer picture of how the lipid droplet metabolism is regulated.

\section{Function As a Nutritional Sensor}

\section{Active pathways in the fat body that regulate the body growth and fly aging}

Drosophila body size is determined during larval stages, that is to say the final adult fly size depends on how fast the larvae grow and when they stop growing before metamorphosis [35,71-73]. In this, nutrition is the key regulator of developmental timing in animals. In the Drosophila fat body, two pathways are active to maintain the nutrition homeostasis. These are the insulin/insulin like growth factor (IGF) signaling (IIS) pathway and the target of rapamycin (TOR) pathway. Both of these can regulate the nutrient uptake, storage and metabolism.

The TOR signaling regulates the rate of growth mainly through adjusting the cellular biosynthetic capacity, while the Insulin-like signaling regulates tissue growth, largely through the phosphatidylinositol 3-kinase (PI3K)/AKT protein kinase pathway
[66-68]. These two pathways can function either independently or together as a linear insulin/Akt/TOR signaling network. The insulinlike polypeptide (DILP) with insulin-like growth factor binding proteins (IGF-BPs) binds the Insulin receptor (InR) and activates the IIS pathway $[69,70]$. The IIS pathway, on one hand, promotes cell growth via TOR which controls protein synthesis and autophagy, on the other, it contributes to energy homeostasis by regulating carbohydrate storage and enhances translation through repressing FoxO [71-76]. TOR signaling also can be activated by free amino acids present in the cell [52].

Attenuation of TOR activity in the fat body results in a decreased final body size without affecting PI3K activity [77], while suppression of InR or PI3K in the fat body decreases the animal's growth rate $[78,79]$. Conversely, activation of Akt in the fat body rescues the small body size induced by immune responses [80]. As one of the downstream transcription factors of insulin signaling, the forkhead protein, FoxO, is inhibited by Akts through phosphorylation, and knockdown of FoxO in the fat body will increase the final pupal size $[81,82]$.

In multiple organisms, nutrient-sensing pathways have also been proven to play a function in aging. When the insulin-like receptor or its receptor substrate, chico, are mutated, or when insulin-producing cells are ablated, the lifespan of the animals is extended by more than $50 \%$ [83-85]. When dFoxO was over-expressed in the abdominal fat body in adults fed on a low-yeast diet or in the head fat body of adults fed on a high-yeast diet, both the systemic IIS signaling in peripheral tissues was reduced and an extended lifespan of the fly was seen $[86,87]$.

The steroid hormone 20-hydroxyecdysone (20E) is another important signal in the larval fat body that integrates with the insulin signaling pathway to monitory the fly's nutritional status. 20E signaling antagonizes IIS in the fat body and promotes autophagy within the fat body tissue [88]. It also can attenuate Myc activity in the fat body to suppresses peripheral insulin signaling and body growth $[82,89]$, where miR- 8 acts as the critical molecular linker for this mediation [90]. 20E also plays a central role in controlling the length of the larval stages [39].

The IIS/TOR pathways are highly conserved throughout the animal kingdom. Further studies of these highly conserved pathways in the Drosophila fat body will likely provide deeper understanding of the control of puberty and maturation in humans and shed light on agerelated diseases such as cancer, obesity and diabetes.

\section{Multiple factors involved in the regulation of body growth and life aging in the fat body}

As a critical nutritional sensor regulating the body's development, the fat body can monitor the nutritional status of the organism and respond by producing various growth factors to coordinate the growth of multiple tissues. Several such factors, derived from the fat body, which regulate the growth and life aging, have been identified.

Slimfast (slif) and minidisks are two amino acid transporters in the fat body. Their knockdown results in reduced larval growth and small adults. Minidisk, predominately expressed in the fat body, is also necessary for imaginal disc proliferation [77,91].

The insulin family peptides have been well studied and are known to play important roles in the regulation of growth and metabolism. In Drosophila, eight insulin-like peptides (DILP1-8) have been identified, 
having unique properties and different tissue and temporal expression patterns [2,92-95]. One of these, DILP6, is expressed extensively in the fat body during larval and adult stages and is directly induced by $20 \mathrm{E}$. DILP6 mutants show reduced adult body size through a decrease in total cell numbers, and overexpression of DILP6 in adult fat body accumulates more energy storage and improves oxidative stress resistance, as well as lifespan [96-98]. In the adult fly, DILP6 transcription is regulated by $\mathrm{dFoxO}$ and correlates with a decrease in DILP2 release, resulting in reduced insulin signaling [99]. However, the factors transmitting signals from the dilp6 of the fat body to the insulin-producing cells (IPCs) of the brain remain unidentified. DILP2, 3 and 5 are produced in the brain and they have a cross-talk with DIL6 in the fat body. When dilps2, 3, and 5 are deleted, an increase in the expression of dilp6 in the fat body becomes apparent. However, a mutant of dilp6 remains unaffected in its brain's dilps expression. Triple dilp 2, 3, 5 mutants and single dilp6 mutants are both viable, but deletion of all 4 dilps causes lethality [99]. As these neuropeptides usually react together and with the difficulty in defining each of their functions separately, and also as the IPCs secrete other additional peptides, the phenotypes associated with deletion of DILPs may not be solely due to the loss of DILPs. Further insight into the communications within the fat body and its connections with other regulators will provide a clearer picture of this mechanism.

The Unpaired 2 hormone (Upd2) has also been identified as a hormone factor that promotes Dilp secretion from IPCs. It is a cytokine member of the unpaired family secreted from the fat body of well-fed larvae. Upd2 expression in the fat body is not induced by amino acids, but by fat and sugar. Upd2 activates JAK/STAT signaling in GABAergic neurons and promotes Dilps release from IPCs (Geminard et al. 2009). Knockdown of fat body Upd2 decreases the final adult body size by preventing the release of Dilp2 from IPCs [3,100-101]. Since both Upd2 and DILP6 can regulate DILP's secretion from IPCs, whether there exists a cross between their actions or just two parallel pathways, requires further confirmation.

Another important factor, quite dissimilar to Upd2, which can certainly affect the dilp6-mRNA levels is dMyc. As a downstream transcription factor of the TOR pathway, dMyc regulates ribosome biogenesis, and protein synthesis. Under starvation, dMyc mRNA in the fat body can be sustained by FoxO transcriptional activity [74, 102-104]. At the late third instar stage, dMyc expression in the fat body is reduced by ecdysone signaling, thus permitting the onset of metamorphosis [105]. Overexpression or knockdown of dMyc in the fat body increases or decreases final pupal size, respectively [82]. Expression of dMyc in the fat body diminishes the ability to retain DILP2 in the brain during starvation. In addition, dMyc-induced regulation of systemic growth, fat storage and resistance to starvation requires the expression of Desat1 in the fat body, a key enzyme necessary for the formation of monosaturated fatty acids and lipid biosynthesis [106-107]. Another transcription factor, DREF, also links TOR activity to ribosome biogenesis and growth [108].
In the adult fat body, silent information 2 (Sir2 or Sirtuin) is a key regulator of longevity in a diet-dependent manner [109]. Lack of Sir2 increases fat deposition which impairs the survival of flies under starvation conditions [110]. Since Sir2 has an interplay with the dFoxO and dilp5, knockdown of dSir2 in the fat body leads to an increase in dilp5 expression which attenuates the dFoxO-dependent lifespan extension. Conversely, overexpression of dSir2 results in decreased dilp5 mediated insulin signaling [110-112].

The factors described above all have tight communication with the DILPs secreted from the brain. It has been shown that the neuropeptides regulate the feeding behavior of Drosophila [113]. However, the related neural circuits of this process are little known and future studies will be needed, especially to clarify how such circuits effect the fat body to regulate alternative behaviors and therefore affect metabolic homeostasis and regulate lifespan.

There have also been some factors in the fat body, the expression of which are seen to be affected by starvation. These include the Acidlabile subunit (ALS), Imaginal morphogenesis protein-Late 2 (ImpL2), and Neural Lazarillo (NLaz). ALS is a binding partner of IGF-1. It has been reported that ALS is expressed in the larval fat body and its expression is severely suppressed by starvation. ALS's affect on body size depends on the nutritional conditions of rearing. Specifically, depletion of ALS in the fat body suppresses body growth on normal feed, but promotes growth under starvation [114-115]. Imp-L2 is a binding partner of DILPs. Under starvation its expression is increased in the fat body in a manner converse to that of ALS. Imp-L2 can form a complex with ALS and Dilp2, which antagonizes Dilps' activity [116-117]. Nlaz is a Drosophila Lipocalin family member and its expression is induced by starvation, oxidative stress, and JNK signaling [118]. NLaz mutant flies exhibit a larger body size and increased systemic insulin signaling. Overexpression of NLaz specifically in the fat body suppresses insulin signaling in oocyte nurse cells as well as affecting the final body size. Fat body specific depletion of NLaz prevents hyperglycemia, otherwise induced by a high sugar diet $[118,119]$.

In summary, systemic growth, as regulated by the fat body, involves integrated pathways and various factors (Figure 2). During larval verses adult phases, the effects of the signalings and factors described above contain remarkable differences. During the larval stage they mainly regulate tissues' growth, while in adults they are largely related to lifespan, resistance to stress, and fecundity. In addition, many factors mediating the regulation of signalings present different or opposite effects depending upon their occurrence under normal nutritional conditions as opposed to those of starvation or stress. This all makes the work more complex. Research on the mechanism of the interactions between different tissues will be an important step in understanding the signaling regulation on body growth and aging. Uncovering novel modulators within the signaling pathways is also an urgent work to be conducted concurrently. 


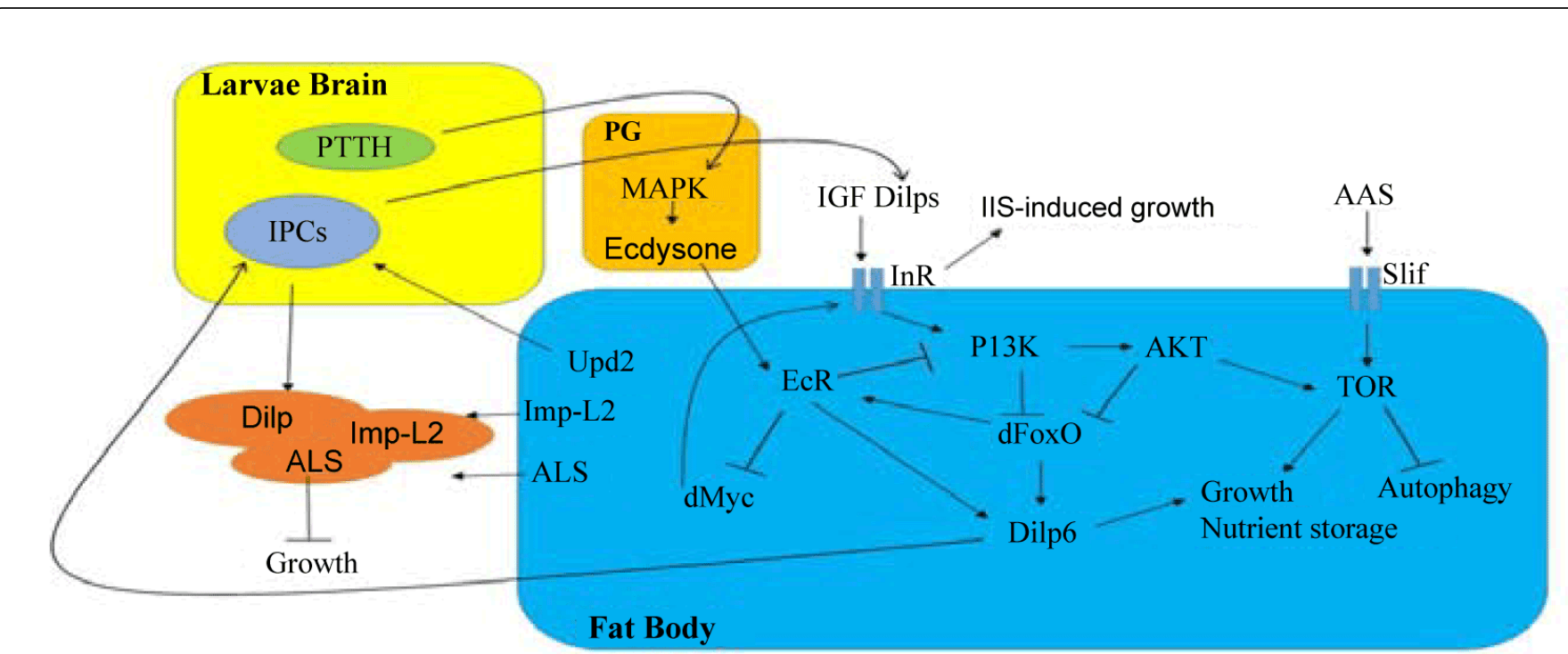

Figure 2: Model of systemic growth regulated by the fat body.

EcR activation inhibits insulin signaling and growth partly through downregulation of dMyc expression. EcR also inhibits PI3K signaling to promote dFoxO to activate the expression of Dilp6. EcR itself also can directly induce the Dilp6's expression. TOR signaling can be activated both by PI3K/AKT signaling and amino acids, which inhibit autophagy and promote growth. The ALS and Imp-L2, that are secreted from the fat body with Dilp2, form a complex which antagonizes growth and Dilps' activity. Both the Dilp6 and Upd2 can remotely control the release of dilps from the IPCs. (Only part key factors are presented in the image. Arrows indicate a positive regulation. Blunt-ended lines indicate a negative regulation).

\section{Conclusions}

The Drosophila fat body provides an ideal model system for studying the molecular mechanisms that regulate the development of insects. As a multifunctional tissue, the fat body is important not only as an energy reservoir and nutritional sensor during development, but also as a hormone producer, crosstalking with other tissues and coordinating metabolic homeostasis. More work is required to further characterize fat body precursor cells and reveal the mechanism of development, differentiation and maturation of the fat body before a clear and full picture of the physiological functions of the fat body can be more fully completely understood. In the meantime, any applicability from Drosophila to the mammalian system regarding body growth and adult longevity requires further research. More research should also be focused on the mechanisms underlying the multiple factors, pathways and networks that are active in the fat body involved in the regulation of the metabolism.

\section{Acknowledgments}

The authors thank Professor Yang X., Ge W., Wood C.and Zheng $\mathrm{H}$. for critical reading of the manuscript. This work was supported by National Basic Research Program of China to Yan.Q. and Yang X. (973 Program, 2012CB966804 and 2013CB945600).

\section{Author Contributions}

Zhang Y wrote the manuscript, Xi Y. revised the paper.

\section{References}

1. Hansen IA, Attardo GM, Roy SG, Raikhel AS (2005) Target of rapamycin-dependent activation of S6 kinase is a central step in the transduction of nutritional signals during egg development in a mosquito. J BiolChem 280: 20565-20572.

2. Sousa-Nunes R, Yee LL, Gould AP (2011) Fat cells reactivate quiescent neuroblasts via TOR and glial insulin relays in Drosophila. Nature 471: 508-512.

3. Géminard C, Rulifson EJ, Léopold P (2009) Remote control of insulin secretion by fat cells in Drosophila. Cell Metab 10: 199-207.

4. Lanet E, Gould AP, Maurange C (2013) Protection of neuronal diversity at the expense of neuronal numbers during nutrient restriction in the Drosophila visual system. Cell Rep 3: 587-594.

5. Ohtsu T, Kimura MT, Hori SH (1992) Energy storage during reproductive diapause in the Drosophila melanogaster species group. J compphysio B 162: 203-208.

6. Athenstaedt K, Daum G (2006) The life cycle of neutral lipids: synthesis, storage and degradation. Cell Mol Life Sci 63: 1355-1369.

7. Beller M, Riedel D, Jänsch L, Dieterich G, Wehland J, et al. (2006) Characterization of the Drosophila lipid droplet subproteome. Mol Cell Proteomics 5: 1082-1094.

8. Grönke S, Mildner A, Fellert S, Tennagels N, Petry S, et al. (2005) Brummer lipase is an evolutionary conserved fat storage regulator in Drosophila. Cell Metab 1: 323-330.

9. Beller M, Bulankina AV, Hsiao HH, Urlaub H, Jäckle H, et al. (2010) PERILIPIN-dependent control of lipid droplet structure and fat storage in Drosophila. Cell Metab 12: 521-532.

10. Beller M, Riedel D, Jänsch L, Dieterich G, Wehland J, et al. (2006) Characterization of the Drosophila lipid droplet subproteome. Mol Cell Proteomics 5: 1082-1094.

11. Bond ND, Nelliot A, Bernardo MK, Ayerh MA, Gorski KA, et al. (2011) BFTZ-F1 and Matrix metalloproteinase 2 are required for fat-body remodeling in Drosophila. DevBiol 360: 286-296. 
12. Kawamura K, Shibata T, Saget O, Peel D, Bryant PJ (1999) A new family of growth factors produced by the fat body and active on Drosophila imaginal disc cells. Development 126: 211-219.

13. Hoshizaki DK (1994) Krüppel expression during postembryonic development of Drosophila. DevBiol 163: 133-140.

14. Technau GM (1987) A single cell approach to problems of cell lineage and commitment during embryogenesis of Drosophila melanogaster. Development 100: 1-12.

15. Hartenstein V, Jan Y (1992) Studying Drosophila embryogenesis with PlacZ enhancer trap lines. Roux's Arch DevBiol 201: 194-220.

16. Lockett TJ, Ashburner M (1989) Temporal and spatial utilization of the alcohol dehydrogenase gene promoters during the development of Drosophila melanogaster. DevBiol 134: 430-437.

17. Mirre C, Cecchini JP, Le Parco Y, Knibiehler B (1988) De novo expression of a type IV collagen gene in Drosophila embryos is restricted to mesodermal derivatives and occurs at germ band shortening. Development 102: 369-376.

18. Mlodzik M, Hiromi Y, Weber U, Goodman CS, Rubin GM (1990) The Drosophila seven-up gene, a member of the steroid receptor gene superfamily, controls photoreceptor cell fates. Cell 60: 211-224.

19. Azpiazu N, Lawrence PA, Vincent JP, Frasch M (1996) Segmentation and specification of the Drosophila mesoderm. Genes Dev 10: 3183-3194.

20. Hoshizaki DK, Blackburn T, Price C,Ghosh M, Miles K (1994) Embryonic fat-cell lineage in Drosophila melanogaster. Development 120: 2489-2499.

21. HoshizakiDK, Lunz R, Ghosh M, Johnson W(1995) Identification of fatcell enhancer activity in Drosophila melanogaster using P-element enhancer traps. Genome 38: 497-506.

22. Riechmann V, Rehorn KP, Reuter R, LeptinM(1998) The genetic control of the distinction between fat body and gonadal mesoderm in Drosophila. Development 125: 713-23.

23. Miller JM, Oligino T, Pazdera M, López AJ, Hoshizaki DK (2002) Identification of fat-cell enhancer regions in Drosophila melanogaster. Insect MolBiol 11: 67-77.

24. Hayes SA, Miller JM, Hoshizaki DK (2001) serpent, a GATA-like transcription factor gene, induces fat-cell development in Drosophila melanogaster. Development 128: 1193-1200.

25. Sam S, Leise W, Hoshizaki DK (1996) The serpent gene is necessary for progression through the early stages of fat-body development. MechDev 60: 197-205.

26. Tysell B, Butterworth FM (1978) Different rate of protein granule formation in the larval fat body of Drosophila melanogaster. Journal of Insect Physiology 24: 201-206.

27. Butterworth FM, Emerson L, Rasch EM (1988) Maturation and degeneration of the fat body in the Drosophila larva and pupa as revealed by morphometric analysis. Tissue Cell 20: 255-268

28. Hackl H, Burkard TR, Sturn A, Rubio R, Schleiffer A, et al. (2005) Molecular processes during fat cell development revealed by gene expression profiling and functional annotation. Genome Biol 6: R108.

29. Britton JS, Edgar BA (1998) Environmental control of the cell cycle in Drosophila: nutrition activates mitotic and endoreplicative cells by distinct mechanisms. Development 125: 2149-2158.

30. Larsen WJ (1976) Cell remodeling in the fat body of an insect. Tissue Cell 8: 73-92.

31. Nelliot A, Bond N, Hoshizaki DK (2006) Fat-body remodeling in Drosophila melanogaster. Genesis 44: 396-400.

32. Davidowitz G, D'Amico LJ, Nijhout HF (2003) Critical weight in the development of insect body size. EvolDev 5: 188-197.

33. Marchal E, Vandersmissen HP, Badisco L, Van de Velde S, Verlinden H, et al. (2010) Control of ecdysteroidogenesis in prothoracic glands of insects: a review. Peptides 31: 506-519.

34. McBrayer Z, Ono H, Shimell M, Parvy JP, Beckstead RB, et al. (2007) Prothoracicotropic hormone regulates developmental timing and body size in Drosophila. Dev Cell 13: 857-871.
35. Rewitz KF, Yamanaka N, Gilbert LI, O'Connor MB (2009) The insect neuropeptide PTTH activates receptor tyrosine kinase torso to initiate metamorphosis. Science 326: 1403-1405.

36. Gibbens YY, Warren JT, Gilbert LI, O'Connor MB (2011) Neuroendocrine regulation of Drosophila metamorphosis requires TGFbeta/Activin signaling. Development 138: 2693-2703.

37. Ou Q, Magico A, King-Jones K (2011) Nuclear receptor DHR4 controls the timing of steroid hormone pulses during Drosophila development. PLoSBiol 9: e1001160.

38. Rewitz KF, Larsen MR, Lobner-Olesen A, Rybczynski R, O'Connor MB, et al. (2009) phosphoproteomics approach to elucidate neuropeptide signal transduction controlling insect metamorphosis. Insect biochemistry and molecular biology 39: 475-83.

39. Bond ND, Hoshizaki DK, Gibbs AG (2010) The role of 20hydroxyecdysone signaling in Drosophila pupal metabolism. Comparative biochemistry and physiology. Part A, Molecular \& integrative physiology 157: 398-404.

40. Liu H, Wang J, Li S (2014) E93 predominantly transduces 20hydroxyecdysone signaling to induce autophagy and caspase activity in Drosophila fat body. Insect BiochemMolBiol 45: 30-39.

41. Nikoletopoulou V, Markaki M, Palikaras K, Tavernarakis N (2013) Crosstalk between apoptosis, necrosis and autophagy. BiochimBiophysActa 1833: 3448-3459.

42. Liu Y, Sheng Z, Liu H, Wen D, He Q, et al. (2009) Juvenile hormone counteracts the bHLH-PAS transcription factors MET and GCE to prevent caspase-dependent programmed cell death in Drosophila. Development 136: 2015-2025.

43. Li M, Mead EA, Zhu J (2011) Heterodimer of two bHLH-PAS proteins mediates juvenile hormone-induced gene expression. ProcNatlAcadSci U S A 108: 638-643.

44. Page-McCaw A, Ewald AJ, Werb Z (2007) Matrix metalloproteinases and the regulation of tissue remodelling. Nat Rev Mol Cell Biol 8: 221-233.

45. Aguila JR, Suszko J, Gibbs AG, Hoshizaki DK (2007) The role of larval fat cells in adult Drosophila melanogaster. J ExpBiol 210: 956-963.

46. Takeuchi K, Reue K (2009) Biochemistry, physiology, and genetics of GPAT, AGPAT, and lipin enzymes in triglyceride synthesis. Am J PhysiolEndocrinolMetab 296: E1195-1209.

47. Beller M, Bulankina AV, Hsiao HH, Urlaub H, Jäckle H, et al. (2010) PERILIPIN-dependent control of lipid droplet structure and fat storage in Drosophila. Cell Metab 12: 521-532.

48. Kühnlein RP (2011) The contribution of the Drosophila model to lipid droplet research. Prog Lipid Res 50: 348-356.

49. Murphy DJ (2012) The dynamic roles of intracellular lipid droplets: from archaea to mammals. Protoplasma 249: 541-585.

50. Brasaemle DL (2007) Thematic review series: adipocyte biology. The perilipin family of structural lipid droplet proteins: stabilization of lipid droplets and control of lipolysis. J Lipid Res 48: 2547-2559.

51. Gäde G, Auerswald L (2003) Mode of action of neuropeptides from the adipokinetic hormone family. Gen Comp Endocrinol 132: 10-20.

52. Grönke S, Müller G, Hirsch J, Fellert S, Andreou A, et al. (2007) Dual lipolytic control of body fat storage and mobilization in Drosophila. PLoSBiol 5: el37.

53. Olofsson SO, Boström P, Andersson L, Rutberg M, Perman J, et al. (2009) Lipid droplets as dynamic organelles connecting storage and efflux of lipids. BiochimBiophysActa 1791: 448-458.

54. Guo Y, Walther TC, Rao M, Stuurman N, Goshima G, et al. (2008) Functional genomic screen reveals genes involved in lipid-droplet formation and utilization. Nature 453: 657-661.

55. Grönke S, Mildner A, Fellert S, Tennagels N, Petry S, et al. (2005) Brummer lipase is an evolutionary conserved fat storage regulator in Drosophila. Cell Metab 1: 323-330.

56. Beller M, Sztalryd C, Southall N, Bell M, Jäckle H, et al. (2008) COPI complex is a regulator of lipid homeostasis. PLoSBiol 6: e292. 
57. Birse RT, Choi J, Reardon K, Rodriguez J, Graham S, et al. (2010) Highfat-diet-induced obesity and heart dysfunction are regulated by the TOR pathway in Drosophila. Cell Metab 12: 533-544.

58. Lu X, Gruia-Gray J, Copeland NG, Gilbert DJ, Jenkins NA, et al. (2001 )The murine perilipin gene: the lipid droplet-associated perilipins derive from tissue-specific, mRNA splice variants and define a gene family of ancient origin. Mamm genome 12: 741-749.

59. Bi J, Xiang Y, Chen H, Liu Z, Grönke S, et al. (2012) Opposite and redundant roles of the two Drosophila perilipins in lipid mobilization. J Cell Sci 125: 3568-3577.

60. Teixeira L, Rabouille C, Rørth P, Ephrussi A, Vanzo NF (2003) Drosophila Perilipin/ADRP homologue Lsd2 regulates lipid metabolism. MechDev 120: 1071-1081

61. Grönke S, Beller M, Fellert S, Ramakrishnan H, Jäckle H, et al. (2003) Control of fat storage by a Drosophila PAT domain protein. CurrBiol 13: 603-606.

62. Li Z, Thiel K, Thul PJ, Beller M, Kühnlein RP, et al. (2012) Lipid droplets control the maternal histone supply of Drosophila embryos. CurrBiol 22: 2104-2113.

63. Jung A, Hollmann M, Schäfer MA (2007) The fatty acid elongase NOA is necessary for viability and has a somatic role in Drosophila sperm development. J Cell Sci 120: 2924-2934.

64. Renault AD, Kunwar PS, Lehmann R (2010) Lipid phosphate phosphatase activity regulates dispersal and bilateral sorting of embryonic germ cells in Drosophila. Development 137: 1815-1823.

65. Guan XL, Cestra G, Shui G, Kuhrs A, Schittenhelm RB, et al. (2013) Biochemical membrane lipidomics during Drosophila development. Dev Cell 24: 98-111.

66. Layalle S, Arquier N, Léopold P (2008) The TOR pathway couples nutrition and developmental timing in Drosophila. Dev Cell 15: 568-577.

67. Wullschleger S, Loewith R, Hall MN (2006) TOR signaling in growth and metabolism. Cell 124: 471-484.

68. Zhang H, Stallock JP, Ng JC, Reinhard C, Neufeld TP (2000) Regulation of cellular growth by the Drosophila target of rapamycindTOR. Genes Dev 14: 2712-2724.

69. Engelman JA, Luo J, Cantley LC (2006) The evolution of phosphatidylinositol 3-kinases as regulators of growth and metabolism. Nat Rev Genet 7: 606-619.

70. Manning BD, Cantley LC (2007) AKT/PKB signaling: navigating downstream. Cell 129: 1261-1274.

71. Radimerski T, Montagne J, Hemmings-Mieszczak M, Thomas G (2002) Lethality of Drosophila lacking TSC tumor suppressor function rescued by reducing dS6K signaling. Genes Dev 16: 2627-2632.

72. Dann SG, Thomas G (2006) The amino acid sensitive TOR pathway from yeast to mammals. FEBS Lett 580: 2821-2829.

73. Pritchett TL, McCall K (2012) Role of the insulin/Tor signaling network in starvation-induced programmed cell death in Drosophila oogenesis. Cell Death Differ 19: 1069-1079.

74. Parisi F, Riccardo S, Daniel M, Saqcena M, Kundu N, et al. (2011) Drosophila insulin and target of rapamycin (TOR) pathways regulate GSK3 beta activity to control Myc stability and determine Myc expression in vivo. BMC Biol 9: 65.

75. Partridge L, Alic N, Bjedov I, Piper MD (2011) Ageing in Drosophila: the role of the insulin/Igf and TOR signalling network. ExpGerontol 46: 376-381.

76. Grewal SS (2009) Insulin/TOR signaling in growth and homeostasis: a view from the fly world. Int J Biochem Cell Biol 41: 1006-1010.

77. Colombani J, Raisin S, Pantalacci S, Radimerski T, Montagne J, et al. (2003) A nutrient sensor mechanism controls Drosophila growth. Cell 114: 739-749.

78. Hyun S, Lee JH, Jin H, Nam J, Namkoong B, et al. (2009) Conserved MicroRNA miR-8/miR-200 and its target USH/FOG2 control growth by regulating PI3K. Cell 139: 1096-1108.
79. Britton JS, Lockwood WK, Li L, Cohen SM, Edgar BA (2002) Drosophila's insulin/PI3-kinase pathway coordinates cellular metabolism with nutritional conditions. Dev Cell 2: 239-249.

80. DiAngelo JR, Bland ML, Bambina S, Cherry S, Birnbaum MJ (2009) The immune response attenuates growth and nutrient storage in Drosophila by reducing insulin signaling. ProcNatlAcadSci U S A 106: 20853-20858.

81. Arden KC (2008) FOXO animal models reveal a variety of diverse roles for FOXO transcription factors. Oncogene 27: 2345-2350.

82. Delanoue R, Slaidina M, Léopold P (2010) The steroid hormone ecdysone controls systemic growth by repressing dMyc function in Drosophila fat cells. Dev Cell 18: 1012-1021.

83. Clancy DJ, Gems D, Harshman LG, Oldham S, Stocker H, et al. (2001) Extension of life-span by loss of CHICO, a Drosophila insulin receptor substrate protein. Science 292: 104-106.

84. Tu MP, Epstein D, Tatar M (2002) The demography of slow aging in male and female Drosophila mutant for the insulin-receptor substrate homologue chico. Aging Cell 1: 75-80.

85. Tatar M, Kopelman A, Epstein D, Tu MP, Yin CM, et al. (2001) A mutant Drosophila insulin receptor homolog that extends life-span and impairs neuroendocrine function. Science 292: 107-110.

86. Min KJ, Yamamoto R, Buch S, Pankratz M, Tatar M (2008) Drosophila lifespan control by dietary restriction independent of insulin-like signaling. Aging Cell 7: 199-206.

87. Hwangbo DS, Gershman B, Tu MP, Palmer M, Tatar M (2004) Drosophila dFOXO controls lifespan and regulates insulin signalling in brain and fat body. Nature 429: 562-566.

88. Rusten TE, Lindmo K, Juhász G, Sass M, Seglen PO, et al. (2004) Programmed autophagy in the Drosophila fat body is induced by ecdysone through regulation of the PI3K pathway. Dev Cell 7: 179-192.

89. Colombani J, Bianchini L, Layalle S, Pondeville E, Dauphin-Villemant C, et al. (2005) Antagonistic actions of ecdysone and insulins determine final size in Drosophila. Science 310: 667-670.

90. Jin H, Kim VN, Hyun S (2012) Conserved microRNA miR-8 controls body size in response to steroid signaling in Drosophila. Genes Dev 26: 1427-1432.

91. Martin JF, Hersperger E, Simcox A, ShearnA (2000) minidiscs encodes a putative amino acid transporter subunit required non-autonomously for imaginal cell proliferation. MechDev 92: 155-167.

92. Brogiolo W, Stocker H, Ikeya T, Rintelen F, Fernandez R, et al. (2001) An evolutionarily conserved function of the Drosophila insulin receptor and insulin-like peptides in growth control. CurrBiol 11: 213-221.

93. Grönke S, Clarke DF, Broughton S, Andrews TD, Partridge L (2010) Molecular evolution and functional characterization of Drosophila insulin-like peptides. PLoS Genet 6: e1000857.

94. Chell JM, Brand AH (2010) Nutrition-responsive glia control exit of neural stem cells from quiescence. Cell 143: 1161-1173.

95. Kannan K, Fridell YW (2013) Functional implications of Drosophila insulin-like peptides in metabolism, aging, and dietary restriction. Front Physiol 4: 288.

96. Okamoto N, Yamanaka N, Yagi Y, Nishida Y, Kataoka H, et al. (2009) A fat body-derived IGF-like peptide regulates postfeeding growth in Drosophila. Dev Cell 17: 885-891.

97. Slaidina M, Delanoue R, Gronke S, Partridge L, Léopold P (2009) A Drosophila insulin-like peptide promotes growth during nonfeeding states. Dev Cell 17: 874-884.

98. Zhang H, Liu J, Li CR, Momen B, Kohanski RA, et al. (2009) Deletion of Drosophila insulin-like peptides causes growth defects and metabolic abnormalities. ProcNatlAcadSci U S A 106: 19617-19622.

99. Bai H, Kang P, Tatar M (2012) Drosophila insulin-like peptide-6 (dilp6) expression from fat body extends lifespan and represses secretion of Drosophila insulin-like peptide-2 from the brain. Aging Cell 11: 978-985.

100. Wright VM, Vogt KL, Smythe E, Zeidler MP (2011) Differential activities of the Drosophila JAK/STAT pathway ligands Upd, Upd2 and Upd3. Cell Signal 23: 920-927. 
Citation: Zhang Y, Xi Y (2014) Fat Body Development and its Function in Energy Storage and Nutrient Sensing in Drosophila melanogaster. J

Page 8 of 8

101. Rajan A, Perrimon N (2012) Drosophila cytokine unpaired 2 regulates physiological homeostasis by remotely controlling insulin secretion. Cell 151: 123-137.

102. Grewal SS, Li L, Orian A, Eisenman RN, Edgar BA (2005) Mycdependent regulation of ribosomal RNA synthesis during Drosophila development. Nat Cell Biol 7: 295-302.

103. Teleman AA, Hietakangas V, Sayadian AC, Cohen SM (2008) Nutritional control of protein biosynthetic capacity by insulin via Myc in Drosophila. Cell Metab 7: 21-32.

104. Li L, Edgar BA, Grewal SS (2010) Nutritional control of gene expression in Drosophila larvae via TOR, Myc and a novel cis-regulatory element. BMC Cell Biol 11: 7.

105. Kamoshida Y, Fujiyama-Nakamura S, Kimura S, Suzuki E, Lim J, et al (2012)Ecdysone receptor (EcR) suppresses lipid accumulation in the Drosophila fat body via transcription control. Biochemical and biophysical research communications 421: 203-207.

106. Parisi F, Riccardo S, Zola S, Lora C, Grifoni D, et al. (2013) dMyc expression in the fat body affects DILP2 release and increases the expression of the fat desaturase Desat1 resulting in organismal growth. DevBiol 379: 64-75.

107. Mauvoisin D, Mounier C (2011) Hormonal and nutritional regulation of SCD1 gene expression. Biochimie 93: 78-86.

108. Killip LE, Grewal SS (2012) DREF is required for cell and organismal growth in Drosophila and functions downstream of the nutrition/TOR pathway. DevBiol 371: 191-202.

109. Banerjee KK, Ayyub C, Ali SZ, Mandot V, Prasad NG, et al. (2012) dSir2 in the adult fat body, but not in muscles, regulates life span in a dietdependent manner. Cell Rep 2: 1485-1491.

110. Banerjee KK, Ayyub C, Sengupta S, Kolthur-Seetharam U (2012) dSir2 deficiency in the fatbody, but not muscles, affects systemic insulin signaling, fat mobilization and starvation survival in flies. Aging (Albany NY) 4: 206-223.

111. Banerjee KK, Ayyub C, Sengupta S, Kolthur-Seetharam U (2013) Fat body dSir2 regulates muscle mitochondrial physiology and energy homeostasis nonautonomously and mimics the autonomous functions of dSir2 in muscles. MolCell Biol 33: 252-64.

112. Rogina B, Helfand SL (2004) Sir2 mediates longevity in the fly through a pathway related to calorie restriction. ProcNatlAcadSci U S A 101: 15998-16003.

113. Nässel DR, WintherAM (2010) Drosophila neuropeptides in regulation of physiology and behavior. ProgNeurobiol 92: 42-104

114. Boisclair YR, Rhoads RP, Ueki I, Wang J, Ooi GT (2001) The acid-labile subunit (ALS) of the $150 \mathrm{kDa}$ IGF-binding protein complex: an important but forgotten component of the circulating IGF system. J Endocrinol 170: 63-70.

115. Arquier N, Géminard C, Bourouis M, Jarretou G, Honegger B, et al. (2008) Drosophila ALS regulates growth and metabolism through functional interaction with insulin-like peptides. Cell Metab 7: 333-338.

116. Honegger B, Galic M, Köhler K, Wittwer F, Brogiolo W, et al. (2008) Imp-L2, a putative homolog of vertebrate IGF-binding protein 7, counteracts insulin signaling in Drosophila and is essential for starvation resistance. J Biol 7: 10.

117. Alic N, Hoddinott MP, Vinti G, Partridge L (2011) Lifespan extension by increased expression of the Drosophila homologue of the IGFBP7 tumour suppressor. Aging Cell 10: 137-147.

118. Hull-Thompson J, Muffat J, Sanchez D, Walker DW, Benzer S, et al. (2009) Control of metabolic homeostasis by stress signaling is mediated by the lipocalinNLaz. PLoS Genet 5: e1000460.

119. Pasco MY, Léopold P (2012) High sugar-induced insulin resistance in Drosophila relies on the lipocalin Neural Lazarillo. PLoS One 7: e36583. 